Proc. Indian Acad. Sci. (Chem. Sci.), Vol. 89, Number 3, June 1980, pp. 263-267.

(C) Printed in India.

\title{
Complexes of lanthanide nitrates with 2-N-(6-picolyl)-benzamide
}

\author{
N RAJASEKAR and S SOUNDARARAJAN \\ Department of Inorganic and Physical Chemistry, Indian Institute of Science, \\ Bangalore 560012 , India \\ MS received 19 February 1980
}

\begin{abstract}
New complexes of lanthanide nitrates with 2-N-(6-picolyl)-benzamide of the formulae $\mathrm{Ln}_{2}[6-p i c-\mathrm{BA}]_{3}\left[\mathrm{NO}_{3}\right]_{6}(\mathrm{Ln}=\mathrm{Y}$ and $\mathrm{La}-\mathrm{Yb})$ have been prepared and characterised by chemical analysis, infrared, molar conductance and electronic spectral data. Molar conductance data along with IR data point to the presence of co-ordinated nitrate groups. IR spectra prove the bidentate co-ordination of the ligand to the metal ion, through the oxygen of the secondary amide and the nitrogen of the heterocyclic ring. Electronic spectral studies in the visible region suggest an eight co-ordinate geometry around the metal ions.
\end{abstract}

Keywords. Lanthanide nitrates; 2-N-(6-picolyl) benzamide; hypersensitive bands.

\section{Introduction}

Recently, we have started a programme of preparing complexes of lanthanides with heterocyclic amides, having the oxygen of the amide moiety and the heterocyclic nitrogen designed in such a fashion so as to function as a potential bidentate ligand. To start with, we have synthesised and characterised lanthanide nitrate complexes with 2-N-(pyridyl)-benzamide (Rajasekar and Soundararajan 1980). In order to study the effect of the methyl group at the 6-position of the ring in 2-N-(6-picolyl) benzamide on the stoichiometry and other physical properties of the complexes formed compared to the 2-N-(pyridyl)-benzamide complexes, we have synthesised and characterised complexes of lanthanide nitrates with 6-pic-BA and report the same in this paper.

\section{Materials and methods}

\subsection{Materials}

2-amino-6-picoline was obtained from Aldrich Chemicals, USA. Lanthanide oxides ( $99 \cdot 9 \%$ pure) were obtained from Indian Rare Earths, Kerala State. All the other chemicals used were of reagent grade. The solvents were purified by standard methods. 


\subsection{Preparation of the ligand 6-pic-BA}

The ligand was prepared according to the method given by Zeide (1920) by the benzoylation of 2-amino-6-picoline. M.P. $89^{\circ} \mathrm{C}$, Lit. $90^{\circ} \mathrm{C}$.

\subsection{Preparation of the hydrated lanthanide nitrates}

The hydrated lanthanide nitrates were prepared by dissolving the corresponding oxides in $50 \%$ nitric acid and evaporating the solution on a steam-bath.

\subsection{Preparation of lanthanide nitrate complexes}

Hydrated lanthanide nitrate $(1 \mathrm{~mm})$ dissolved in ethylacetate $(5 \mathrm{ml})$ was treated with the ligand $(4 \mathrm{~mm})$. The solution was evaporated on a steam-bath, washed twice with hot chloroform $(10 \mathrm{ml})$ to remove the excess of ligand, if any, and nally dried at the pump ( $c a 3 \mathrm{~mm} / \mathrm{Hg}$ ) at $60^{\circ} \mathrm{C}$ for about $45 \mathrm{~min}$ to get the complex.

\subsection{Analyses}

The metal content of the complexes was estimated by EDTA titrations using xylenol orange as the indicator (Kolthoff and Elwing 1963). The nitrate content was estimated as nitron nitrate (Vogel 1962). The analytical data are presented in table 1 .

\subsection{Physical methods}

The IR spectra of the ligand and complexes in nujol mull in the region $400-4000 \mathrm{~cm}^{-1}$ were recorded on a Carl-Zeiss UR-10 spectrophotometer. Conductance measurements in acetonitrile were carried out in a Siemen's conductivity bridge using an immersion cell (type LTA), previously calibrated with standard $\mathrm{KCl}$ solution. The concentrations of the solutions used were of the order of $0.001 \mathrm{M}$ (table 1).

Table 1. Analytical and molar conductance data of 6-pic-BA complexes.

\begin{tabular}{|c|c|c|c|c|c|}
\hline Complex & $\begin{array}{c}\text { Motal \% } \\
\text { Found (Calc.) }\end{array}$ & $\begin{array}{c}\text { Nitrate } \% \\
\text { Found (Calc.) }\end{array}$ & $\begin{array}{c}\text { Carbon } \% \\
\text { Found (Calc.) }\end{array}$ & $\begin{array}{l}\text { Hydrogen } \% \\
\text { Found (Calc.) }\end{array}$ & $\Lambda^{*}$ \\
\hline $\mathrm{La}_{2}[6-\mathrm{pic}-\mathrm{BA}]_{3}\left[\mathrm{NO}_{3}\right]_{6}$ & $21 \cdot 49(21 \cdot 62)$ & $28.76(28.92)$ & $24 \cdot 10(24 \cdot 26)$ & $1 \cdot 60(1 \cdot 87)$ & 36 \\
\hline $\mathrm{Pr}_{2}[6-\text { pic-BA }]_{3}\left[\mathrm{NO}_{3}\right]_{6}$ & $21 \cdot 76(21 \cdot 86)$ & $28.97(28.83)$ & $24 \cdot 31 \quad(24 \cdot 18)$ & $1 \cdot 73(1 \cdot 86)$ & 46 \\
\hline $\mathrm{Nd}_{2}[6-p i c-B A]_{6}\left[\mathrm{NO}_{3}\right]_{6}$ & $22 \cdot 16(22 \cdot 26)$ & $28 \cdot 70(28 \cdot 70)$ & $24 \cdot 01(24 \cdot 07)$ & $1 \cdot 60(1 \cdot 85)$ & 23 \\
\hline $\mathrm{Ho}_{2}[6-p i c-B A]_{3}\left[\mathrm{NO}_{3}\right]_{6}$ & $24 \cdot 71(24 \cdot 65)$ & $27 \cdot 76(27 \cdot 81)$ & $23 \cdot 32(2,3 \cdot 32)$ & $1.93(1.79)$ & 32 \\
\hline $\mathrm{Er}_{2}[6-\text { pic-BA }]_{3}\left[\mathrm{NO}_{3}\right]_{6}$ & $24 \cdot 90(24 \cdot 92)$ & $27 \cdot 70(27 \cdot 71)$ & $23 \cdot 14 \cdot(23 \cdot 24)$ & $1 \cdot 61(1 \cdot 79)$ & 51 \\
\hline $\mathrm{Yb}_{2}[6-\mathrm{pic}-\mathrm{BA}]_{2}\left[\mathrm{NO}_{3}\right]_{6}$ & $24 \cdot 73(24 \cdot 67)$ & $27 \cdot 38(27 \cdot 47)$ & $22.99(23 \cdot 04)$ & $1 \cdot 93(1 \cdot 77)$ & 48 \\
\hline$Y_{2}[6-p i c-B A]_{3}\left[N_{3}\right]_{6}$ & $14 \cdot 88(15 \cdot 00)$ & $31 \cdot 21(31 \cdot 37)$ & $26 \cdot 14(26 \cdot 31)$ & $2 \cdot 11(2 \cdot 02)$ & 34 \\
\hline
\end{tabular}

* Molar conductance-ohms $\mathrm{sm}^{-1} \mathrm{~mol}^{-1}$. 
Electronic spectra of $\mathrm{Nd}$ and Ho complexes in acetonitrile were recorded in the visible region on a Unicam SP-700A spectrophotometer.

\section{Results and discussion}

Analytical data show that the complexes have the composition $\operatorname{Ln}_{2}[6 \text {-pic-BA] }]_{3}$ $\left[\mathrm{NO}_{3}\right]_{6}(\mathrm{Ln}=\mathrm{Y}$ and $\mathrm{La}-\mathrm{Yb})$. The complexes are soluble in ethanol, methanol, acetone and acetonitrile, but insoluble in benzene, chloroform and carbon tetrachloride. The composition of the complexes shows that the presence of methyl group at 6-position introduces considerable steric hindrance and brings down the number of ligand molecules attached to the metal from two in the $2-\mathrm{N}$-(pyridy1)benzamide complexes to one and half in the present complexes.

Molar conductance values in acetonitrile indicate that the nitrate groups are all non-ionic (Geary 1971).

The principal IR bands and the appropriate assignments are shown in table 2. The presence of amide I band at two frequencies, viz. a strong band at $1675 \mathrm{~cm}^{-1}$ and a weak band at $1685 \mathrm{~cm}^{-1}$ would probably be due to the presence of ligand in two different forms. On complexation, the amide $I$ band shifts to a lower frequency as a result of the co-ordination of the ligand through the oxygen of the secondary amide. This is further substantiated by the increase observed in the amide II, amide IJI and amide IV band frequencies of the complexes compared to the ligand.

Table 2. Important IR bands and their assignment of 6-pic-BA complexes.

\begin{tabular}{|c|c|c|c|c|c|c|c|c|}
\hline 6-pic-BA & $\mathbf{L a}$ & $\operatorname{Pr}$ & $\mathrm{Nd}$ & Ho & Er & $\mathrm{Yb}$ & $Y$ & Assignment \\
\hline .. & $\begin{array}{l}1775 \mathrm{vw} \\
1740 \mathrm{vw}\end{array}$ & $\begin{array}{l}1775 \mathrm{vw} \\
1740 \mathrm{vw}\end{array}$ & $\begin{array}{l}1775 \mathrm{vw} \\
1740 \mathrm{vw}\end{array}$ & $\begin{array}{l}1775 \mathrm{vw} \\
1740 \mathrm{vw}\end{array}$ & $\begin{array}{l}1780 \mathrm{vw} \\
1740 \mathrm{vw}\end{array}$ & $\begin{array}{l}1770 \mathrm{vw} \\
1746 \mathrm{vw}\end{array}$ & $\begin{array}{l}1770 \mathrm{vw} \\
1745 \mathrm{vw}\end{array}$ & $\begin{array}{l}v_{2}\left(\mathrm{~A}_{1}\right)+v_{5}\left(\mathrm{~A}_{1}\right) \text { nitrate } \\
v_{2}\left(\mathrm{~A}_{1}\right)+v_{2}\left(\mathrm{~B}_{2}\right) \text { nitrate }\end{array}$ \\
\hline $1675 \mathrm{vs}$ & $1645 \mathrm{vs}$ & $1650 \mathrm{~s}$ & $1650 \mathrm{~s}$ & $1650 \mathrm{~s}$ & $1650 \mathrm{~s}$ & $1650 \mathrm{~s}$ & $1650 \mathrm{~s}$ & Amide I \\
\hline $1685 w$ & $1635 w$ & $1630 \mathrm{w}$ & $1635 w$ & $1635 \mathrm{w}$ & $1635 \mathrm{w}$ & $1630 \mathrm{w}$ & $1635 w$ & \\
\hline $1605 \mathrm{vs}$ & $1610 \mathrm{~s}$ & $1610 \mathrm{~s}$ & $1614 \mathrm{~s}$ & $1611 \mathrm{~s}$ & $1611 \mathrm{~s}$ & $1610 \mathrm{~s}$ & $1610 \mathrm{~s}$ & Ring $C=C, C=N$ \\
\hline $1535 \mathrm{~s}$ & $1540 \mathrm{~s}$ & $1540 \mathrm{~s}$ & $1540 \mathrm{~s}$ & $1575 \mathrm{vs}$ & $1570 \mathrm{vs}$ & $1570 \mathrm{vs}$ & $1575 \mathrm{vs}$ & Amide II \\
\hline$\cdots$ & $1468 \mathrm{vs}$ & $\begin{array}{l}1470 \mathrm{vs}, \\
\mathrm{br}\end{array}$ & $1460 \mathrm{vs}$ & $\begin{array}{c}1470 \mathrm{~s} \\
\mathrm{br}\end{array}$ & $\begin{array}{c}1470 \mathrm{~s}, \\
\mathrm{br}\end{array}$ & $1460 \mathrm{~s}$ & $1468 \mathrm{~s}$ & $v_{4}\left(\mathrm{~B}_{2}\right)$ nitrate \\
\hline & $1350 \mathrm{~m}$ & $1350 \mathrm{w}$ & $1350 \mathrm{~m}$ & $1350 w$ & $1350 \mathrm{w}$ & $1351 w$ & $1350 \mathrm{w}$ & $v_{1}\left(\mathrm{~A}_{1}\right)$ nitrate \\
\hline $1280 \mathrm{vs}$ & $1290 \mathrm{~m}$ & $\begin{array}{c}1305 \mathrm{~s}, \\
\mathrm{bn}\end{array}$ & $1290 \mathrm{~m}$ & $\begin{array}{c}1305 s, \\
b r\end{array}$ & $\begin{array}{c}1305 \mathrm{~s} \\
\mathrm{br}\end{array}$ & $\begin{array}{c}1305 \mathrm{~s}, \\
\mathrm{bn}\end{array}$ & $\begin{array}{c}1305 \mathrm{~s} \\
\mathrm{br}\end{array}$ & Amide III \\
\hline $1010 \mathrm{~s}$ & $1038 s$ & $1040 \mathrm{vs}$ & $1038 v s$ & $1040 \mathrm{vs}$ & $1040 \mathrm{vs}$ & $1040 \mathrm{vs}$ & $1040 \mathrm{vs}$ & $v_{\mathrm{a}}\left(\mathrm{A}_{1}\right)$ nitrate + ligand \\
\hline 1008sh & $1012 w$ & $1012 w$ & 1012sh & 1012sh & $1012 \mathrm{sh}$ & 1012 sh & 1012sh & \\
\hline$\ddot{\theta}$ & $840 \mathrm{~m}$ & $820 \mathrm{~s}$ & $820 \mathrm{~s}$ & $820 \mathrm{~s}$ & $\begin{array}{l}820 \mathrm{~s} \\
670 \mathrm{~m}\end{array}$ & $\begin{array}{l}820 \mathrm{~s} \\
670 \mathrm{~m}\end{array}$ & $820 \mathrm{~s}$ & $v_{3}\left(\mathrm{~B}_{1}\right)$ nitrate \\
\hline $650 \mathrm{~s}$ & $680 \mathrm{bp}$ & $670 \mathrm{~m}$ & $670 \mathrm{~m}$ & $670 \mathrm{~m}$ & $670 \mathrm{~m}$ & $670 \mathrm{~m}$ & $675 \mathrm{~m}$ & Amide IV \\
\hline $610 \mathrm{vs}$ & $620 w$ & $625 \mathrm{w}$ & $625 \mathrm{w}$ & $625 \mathrm{w}$ & $625 \mathrm{w}$ & $625 \mathrm{w}$ & $625 w$ & $\begin{array}{l}\text { Ring in-plane deforma- } \\
\text { tion }\end{array}$ \\
\hline $420 \mathrm{w}$ & $450 \mathrm{~s}$ & $450 \mathrm{~s}$ & $450 \mathrm{~s}$ & $447 \mathrm{~s}$ & $445 \mathrm{~s}$ & 440 s & $440 \mathrm{~s}$ & $\begin{array}{l}\text { Ring out-of-plane } \\
\text { deformation }\end{array}$ \\
\hline
\end{tabular}

Abbreviations : $\mathrm{s}=$ strong; $\mathrm{vs}=$ very strong; $\mathrm{m}=$ medium; $\mathrm{w}=$ weak; $\mathrm{sh}=$ shoulder, 
The $v_{\mathrm{c} \rightarrow \mathrm{c}}$ and $v_{\mathrm{c}=\mathrm{x}}$ stretching vibrations of the pyridine ring are found at a higher frequency in the complexes compared to the ligand. This is due to an increase in double bond character of the $\mathrm{C}=\mathrm{C}$ and $\mathrm{C}=\mathrm{N}$ bond. An increase in the characteristic ring breathing, ring-in-plane and out-of-plane deformation modes is also observed in all the complexes and such shifts have invariably been noticed in complexes involving pyridine co-ordination. These go to indicate that both the amide oxygen and heterocyclic nitrogen take part in the co-ordination and the ligand acts in a bidentate chelating fashion.

Nitrate groups are capable of bonding to a metal ion in a unidentate or a bidentate fashion. The two situations cannot, in general, be unambiguously distinguished on the basis of the IR data alone.

In the absence of Raman data, the combination bands of the nitrate group which generally appear in the 1700-1800 region have been used for structural assignments of the nitrate groups (Curtis and Curtis 1965; Lever et al 1971). In the present complexes, the presence of two weak bands in the above said region clearly show that the nitrate groups are co-ordinated to the metal ions in a bidentate fashion. It has been shown that $f$-block transition metal prefers bidentate co-ordination of the nitrate groups to monodentate or ionic, which can be attributed to the favourable metal-nitrate interaction for given degree of nitrate-nitrate repulsion (Haque et al 1971).

The electronic spectral data of $\mathrm{Nd}^{3+}$ and $\mathrm{Ho}^{3+}$ complexes are presented in table 3 along with the $J$ level assignments. Sinha's (1966) covalency parameter $\delta$ have been calculated and the positive value of $\delta$ suggests a certain amount of covalency in the metal-ligand bond. The hypersensitive bands in the complexes revealed some splitting on running an expanded spectrum. The shape, position and relative intensities were identical in the solid state spectra taken in nujol mull and solution spectra recorded in acetonitrile. Also, the shapes of the hypersensitive bands resemble markedly the shapes reported in the literature by Karrakar $(1967,1968)$ for some eight-co-ordinate $\beta$-diketonates.

Table 3. Electronic spectral data of 6-pic-BA complexes and their assignments.

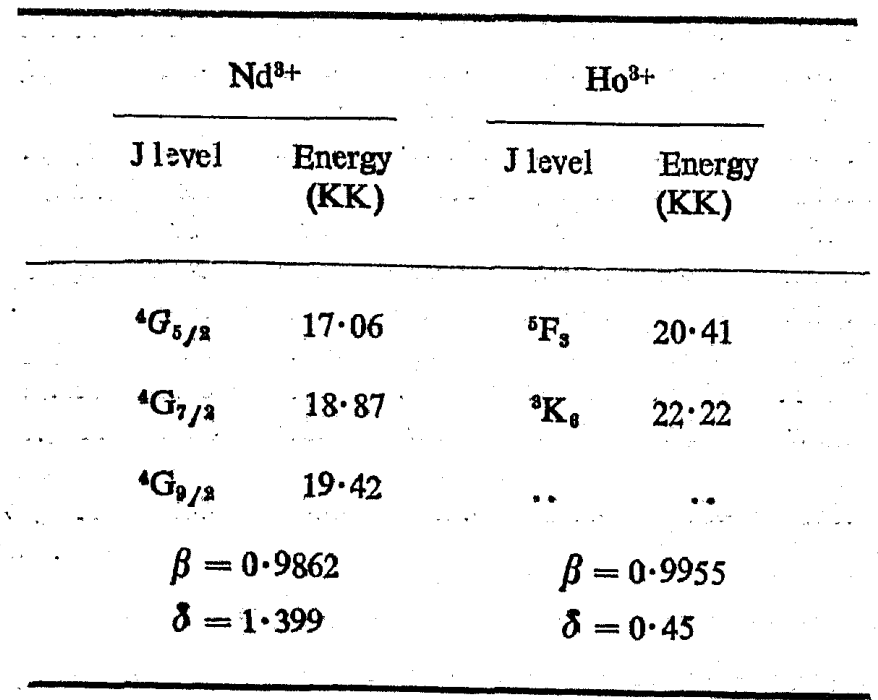


With the available data presented here, an eight co-ordinate geometry can be assigned tentatively for all the complexes.

\section{Acknowledgements}

Sincere thanks are due to Dr V C Jyothi Basu for the microanalytical results. NR is thankful to the authorities of the Indian Institute of Science for a research fellowship.

\section{References}

Curtis N F and Curtis Y M 1965 Inorg. Chem. 4804

Geary W J 1971 Coord. Chem. Rev. 781

Haque Mazhar ul, Caughlam C N, Hart F A and Van Nice R 1971 Inorg. Chem. 10115

Karraker D G 1967 Inorg. Chem. 61863

Karraker D G 1968 Inorg. Chem. 7473

Kolthoff I M and Elwing P J 1963 Treatise on analytical chemistry Part II (New York : Interscience) 857

Lever A B P, Mantovani E and Ramaswamy B P 1971 Can. J. Chem. 491957

Rajasekar N and Soundararajan S 1980 (Communicated)

Sinha S P 1966 Spectrochim. Acta 2257

Vogel A I 1962 A text-book of quantitative inorganic analysis (London: English Language Book Society and Longmans) p. 583

Zeide O A 1920 J. Russ. Phys. Chem. Soc. 50534 